\title{
What Every Traveler KnOWS
}

1. He will not stay and has left another, more familiar life, for weeks or months.

2. Every city has its beautiful women, elegantly dressed, with a slow, sidling sort of walk.

3. Too close a look will show that many are not so beautiful, distance acting suggestively when make-up or features are thick.

4. After only a few weeks the flash of thigh from the vent in a skirt brings a longing he is slow to acknowledge.

5. Your hesitation in approaching it as your own is one mark of your distance from home.

6. You've come wherever you come to be reminded that every city was far away until you approached, domesticated.

7. Another language, another set of customs help you keep your distance.

8. Freshness and loneliness require each other like ground and figure.

9. Flaking stucco, the strata of paint and the cobbled streets reveal time is a sort of distance,

10. because they are not seen, those who were here before us, those we left at home.

11. They are always a long way off, whether it is fifteen kilometers or fifteen miles or fifteen thousand of either.

12. We always managed to ignore the sinking feeling such reflections bring, until we met the longer nights in which we are finding ourselves.

13. Some crumbling wall and the beak of some nose, both encountered before, will probably greet us tomorrow.

14. The old trolley-bus brick bastion they're taking down though it's only ten years old could last longer than they suppose.

15. Because tomorrow comes under similar constraints

16. I wake up where I have to live. 